\title{
Analysis of factors influencing postoperative drainage time in breast cancer
}

\author{
Quanyi Long ${ }^{1}$, Jia Zhang ${ }^{1}$, Jiahao Qi $^{2}$, Yuan Fan ${ }^{1}$, Hongjiang Li ${ }^{1}$ \\ ${ }^{1}$ Department of Breast Surgery, West China Hospital, Sichuan University, Chengdu, China; ${ }^{2}$ Linzi District Center for Disease Control and \\ Prevention, Zibo, China \\ Contributions: (I) Conception and design: Q Long, H Li; (II) Administrative support: None; (III) Provision of study materials or patients: None; (IV) \\ Collection and assembly of data: Q Long, J Zhang, Y Fan, H Li; (V) Data analysis and interpretation: J Zhang, J Qi; (VI) Manuscript writing: All \\ authors; (VII) Final approval of manuscript: All authors. \\ Correspondence to: Hongjiang Li. Department of Breast Surgery, West China Hospital, Sichuan University, No.37 Guoxue Alley, Wuhou District, \\ Chengdu City, China. Email: lihongjiang@sohu.com.
}

Background To investigate the related factors affecting the postoperative indwelling time of drainage tubes (hereinafter referred to as drainage time) in breast cancer (BC) and evaluate the effect of Pseudomonas aeruginosa-mannose-sensitive hemagglutinin (PA-MSHA) preparation on reducing postoperative drainage time.

Methods: The clinical data of 165 BC patients in our hospital, including the postoperative drainage time and occurrence of seroma and related complications (such as fever, incision infection, and flap necrosis) after extubation, were retrospectively analyzed. Univariate, multivariate, and stratified analyses were used to determine the correlations between 15 factors including age, body weight, body mass index (BMI), and PAMSHA preparation, and the postoperative total drainage volume and drainage time.

Results: Age, BMI, and PA-MSHA preparation were independent factors affecting the postoperative drainage volume and drainage time of BC patients. Age and BMI were positively correlated with postoperative drainage volume and drainage time $(\mathrm{P} \leq 0.004, \mathrm{P} \leq 0.037)$. PA-MSHA preparation significantly reduced the postoperative total drainage volume and drainage time $(\mathrm{P}<0.001)$, decreased the incidence of seroma after extubation $(\mathrm{P}=0.024)$, and did not increase complications $(\mathrm{P}>0.05)$.

Conclusions: Obese and elderly patients were at a significantly high risk of a high drainage volume and long drainage time. Local treatment with PA-MSHA preparation had the advantages of reducing postoperative drainage volume, reducing drainage time, preventing seroma, and not increasing complications, and was a safe and effective treatment. For BC patients aged over 60 years and with a BMI $\geq 25$, the intraoperative local spraying of wounds with PA-MSHA preparation to reduce postoperative drainage times is a valuable option.

Keywords: Modified radical mastectomy; drainage time; Pseudomonas aeruginosa-mannose sensitive hemagglutinin (PA-MSHA); body mass index (BMI)

Submitted Sep 07, 2021. Accepted for publication Nov 04, 2021.

doi: 10.21037 /gs-21-697

View this article at: https://dx.doi.org/10.21037/gs-21-697

\section{Introduction}

Breast cancer (BC) is the most frequently occurring cancer in women of childbearing age and has the highest incidence and mortality rate of all malignant tumors in women (1). While surgery is an important treatment for BC, due to its wide scope, the large incision, and the extensive use of an electric scalpel during the operation, postoperative effusion is increased, the drainage volume is increased, and the indwelling time of drainage tubes (hereinafter referred to as drainage time) is prolonged. Prolonged drainage time may lead to infection, flap necrosis, and other complications, 


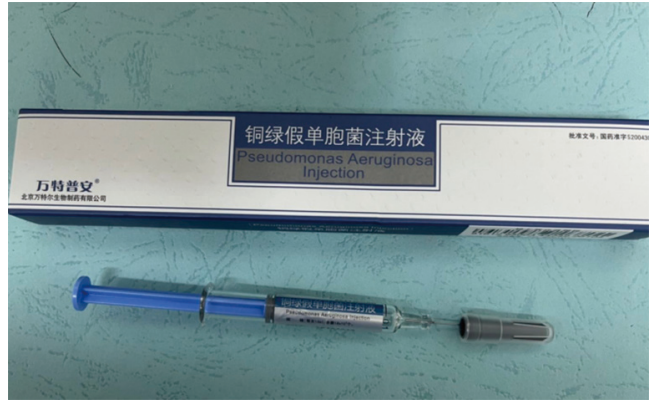

Figure $1 P A-M S H A$ preparation and its outer packaging. PAMSHA, Pseudomonas aeruginosa-mannose sensitive hemagglutinin.

leading to delayed adjuvant treatment, a prolonged recovery period and hospital stay, and a high frequency of outpatient visits, all of which may increase psychological and physical distress and raise medical costs. While the removal of drainage tubes should be performed as soon as possible, premature removal may lead to the formation of seroma (2). However, there is no ideal treatment to effectively reduce the indwelling time of drainage tube. To investigate factors affecting the postoperative drainage time after axillary lymph node dissection for $\mathrm{BC}$ and to provide a reference for the development of methods to shorten it, this study retrospectively analyzed $165 \mathrm{BC}$ patients who underwent modified radical mastectomy (MRM).

We present the following article in accordance with the STROBE reporting checklist (available at https://dx.doi. org/10.21037/gs-21-697).

\section{Methods}

\section{Clinical data}

The study was approved by the ethics committee of the West China Hospital of Sichuan University [NO. 2020(620)]. Written informed consent was obtained prior to the study. The study was conducted in accordance with the Declaration of Helsinki (as revised in 2013).

We retrospectively collected information from patients undergoing MRM without robotic or endoscopic surgery and by the same surgeon in the Department of Breast Surgery, West China Hospital of Sichuan University from March 2019 to December 2019. The inclusion criteria were as follows: (I) female patients undergoing modified radical resection (MRM); (II) exclusion of distant metastasis of BC with chest CT, abdominal CT, gynecological color Doppler ultrasound, and bone scans; (III) pathologically confirmed primary invasive $\mathrm{BC}$; (IV) no past malignant tumors; and (V) first surgery for BC (patients with a prior history of benign breast mass excision were not excluded). The exclusion criteria were as follows: (I) patients who underwent skin grafting in the operation area; (II) pregnancy-associated breast cancer (PABC); and (III) the use of hemostatic agents during the operation. Cases were collected according to the inclusion and exclusion criteria, and electrocoagulation with a monopolar electrode was used for tissue cutting during surgery for all patients. After surgery, one drainage tube was placed in the sternum, and another in the axilla, and all patients received post-surgical follow-up and regular cancer treatment. The surgical data showed some patients received local spraying of the surgical area with 2 $\mathrm{mL}$ of undiluted Pseudomonas aeruginosa-mannose sensitive hemagglutinin (PA-MSHA) preparation (total bacterial count: $1.0 \times 10^{8} \mathrm{cfu} / \mathrm{mL}$ ) intraoperatively. Therefore, 116 patients treated with PA-MSHA preparation were placed in the Pseudomonas aeruginosa (PA) group and ranged in age from 29 to 81 years, with an average age of $51.88 \pm$ 10.281 years. The non-Pseudomonas aeruginosa (non-PA) group comprised of 49 patients who did not receive PAMSHA preparation during surgery, and ranged in age from 33 to 76 years, with an average age of $53.80 \pm 11.543$ years.

PA-MSHA preparation: the PA-MSHA treatment was prepared using a genetically engineered heat-inactivated PA-MSHA strain with meaningful mannose activity capable of inducing tumor cell apoptosis (3-5), and was manufactured by the Beijing Wanter Biopharmaceutical Company, China (Figure 1).

\section{Data collection and evaluation criteria}

The following data were obtained from all included patients: Patient-related variables, including age, height, body mass index (BMI), age at menarche, and menopause, and surgeryrelated variables, including the scope of axillary lymph node dissection, the number of lymph nodes to be examined, the number of lymph node metastases, tumor size, pathological molecular subtype, left/right breast, and the use of PAMSHA preparation and the dose. Postoperative fever, infection, and flap necrosis and the incidence of seroma within one month after extubation were also collected, as well as postoperative total drainage volume and drainage times.

The postoperative total drainage volume was defined as the sum of the daily drainage volume from the first postoperative day to the day of extubation, while drainage 


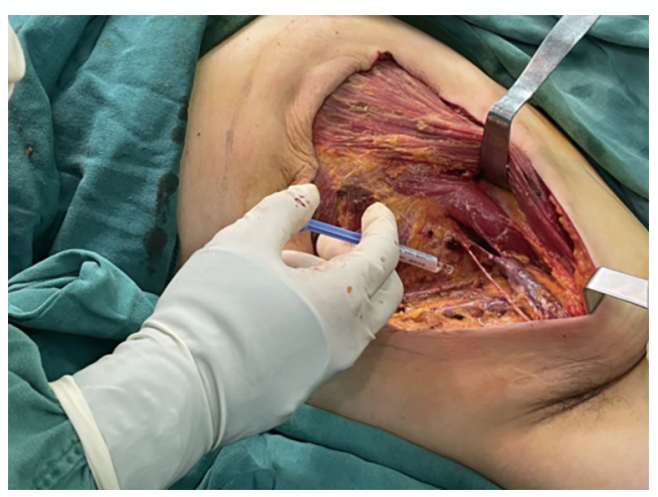

Figure 2 PA-MSHA preparation was sprayed on the wounds in the operation area. PA-MSHA, Pseudomonas aeruginosa-mannose sensitive hemagglutinin.

time was defined as the indwelling time of drainage tubes after both tubes were removed, i.e., the longest indwelling time of one drainage tube.

Observations of wound infection and flap necrosis were recorded when the wound dressing was changed, which occurred every 3 days, and was performed by the same two wound care physical therapists.

In the PA group, after the surgical removal of $\mathrm{BC}$ specimens, PA-MSHA preparation $(2 \mathrm{~mL})$ was sprayed on the wounds in the operation area (Figure 2) and was followed by the placement of two drainage tubes in the same area (a single tube in the sternum, and another in the axilla). The distal end of the tubes were then clamped, and an incision was made with an interrupted full thickness suture. After the incision was closed, the drainage tube clamps were opened, and external low-negative-pressure sustained suction was initiated.

In the non-PA group, after the surgical removal of BC specimens and direct placement of the two drainage tubes (a single drainage tube was placed in the sternum, and another in the axilla), an incision was made with an interrupted fullthickness suture. After the incision was closed, external lownegative-pressure sustained suction was initiated.

The extubation criteria included the following: Drainage volume from a single tube for 2 consecutive days $\leq 10 \mathrm{~mL} /$ day, and the drainage tube was smooth and without seroma.

Overweight and obesity were defined according to the World Health Organization (WHO), which sees a BMI $\geq 25$ considered as overweight, while a $\mathrm{BMI} \geq 30$ is considered as obesity $(6,7)$.

Seroma standard: According to the criteria for the determination of seroma by Marquez (8) and Srivastava (9), seroma is any fluid that accumulates under the skin flap or in the axillary cavity after mastectomy and requires clinical aspiration or image-guided aspiration.

\section{Statistical methods}

(I) SPSS 17.0 software was used for statistical analysis, which were performed using a two-sided test and $\mathrm{P}<0.05$ indicated differences were statistically significant.

(II) Count data are expressed as the number of cases or percentage, and measurement data are expressed as the mean \pm standard deviation $(\bar{x} \pm \mathrm{s})$. These data were compared between the experimental group and the control group, and the differences between the two were assessed using the $t$-test, Mann-Whitney $\mathrm{U}$ test, or chi-square test.

(III) Categorical variables were analyzed using the independent samples $t$-test or the Mann-Whitney $\mathrm{U}$ test, while continuous variables were analyzed with the Pearson correlation analysis for univariate analysis, multivariate linear regression for multivariate analysis, and the Mantel-Haenszel (M-H) test for stratified analysis.

\section{Results}

\section{Population characteristics}

A total of 165 female patients with pathologically confirmed invasive $\mathrm{BC}$ were included, with a mean age of $52.45 \pm 10.67$ years, mean height of $157.59 \pm 5.43 \mathrm{~cm}$, mean weight of $57.18 \pm 7.45 \mathrm{~kg}$, and mean BMI of $23.04 \pm$ $2.89 \mathrm{~kg} / \mathrm{m}^{2}$. Among the patients, $116(70.30 \%)$ received PA-MSHA preparation, and the differences in the baseline data of those in the PA and non-PA groups were not statistically significant $(\mathrm{P}>0.05)$ (Table 1).

The median postoperative total drainage volume was $531 \mathrm{~mL}$, and the median drainage time was 15 days (Table 2).

\section{Univariate analysis}

This showed age ( $\mathrm{r}=0.317, \mathrm{P}=0.001)$, body weight $(\mathrm{r}=0.402$, $\mathrm{P}=0.001)$, BMI $(\mathrm{r}=0.454, \mathrm{P}=0.001)$, age at menarche $(\mathrm{r}=0.157, \mathrm{P}=0.044)$, menopause $(\mathrm{P}=0.034)$, and PA-MSHA preparation $(\mathrm{P}<0.001)$ were significantly correlated with the postoperative total drainage volume, and the application of 
Table 1 Baseline patient characteristics

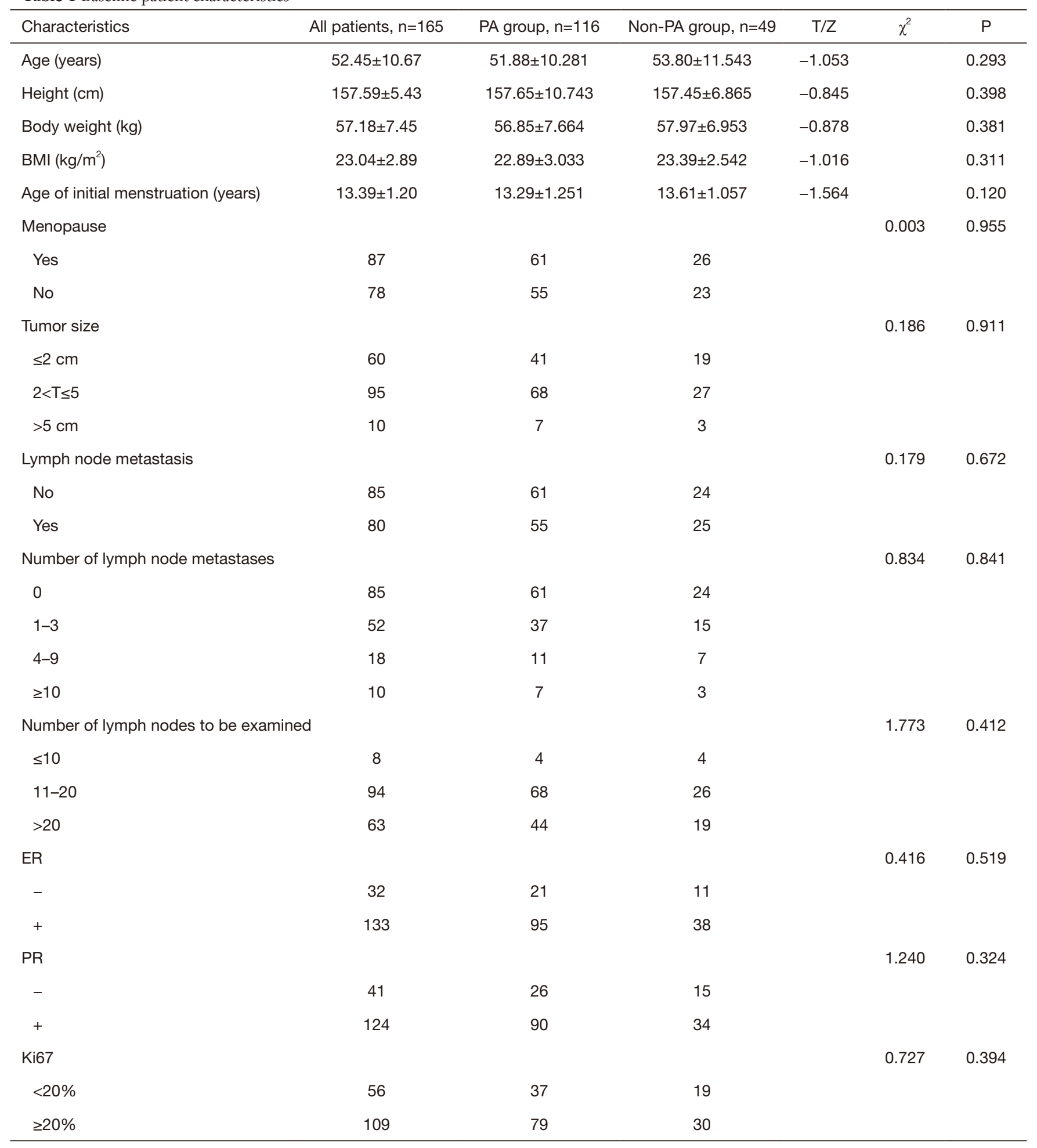

Table 1 (continued) 
Table 1 (continued)

\begin{tabular}{|c|c|c|c|c|c|c|}
\hline Characteristics & All patients, $n=165$ & PA group, $n=116$ & Non-PA group, $n=49$ & $\mathrm{~T} / \mathrm{Z}$ & $x^{2}$ & $\mathrm{P}$ \\
\hline Left & 82 & 60 & 22 & & & \\
\hline Right & 83 & 56 & 27 & & & \\
\hline Subclavian lymph node dissection & & & & & 0.419 & 0.517 \\
\hline No & 133 & 92 & 41 & & & \\
\hline
\end{tabular}

PA, Pseudomonas aeruginosa; BMI, body mass index; ER, estrogen receptor; PR, progesterone receptor; Ki67,Ki-67 Antigen.

Table 2 Description of data related to postoperative drainage

\begin{tabular}{lccc}
\hline Characteristics & Cases & $\bar{x} \pm \mathrm{S}$ & Median \\
\hline Total drainage volume $(\mathrm{mL})$ & & $672.68 \pm 432.30$ & 531 \\
$<530$ & 82 & & \\
$\geq 530$ & 83 & & \\
Drainage time (days) & & $15.62 \pm 6.10$ & 15 \\
$<15$ & & & \\
$\geq 15$ & 79 & & \\
\hline
\end{tabular}

PA-MSHA preparation significantly reduced this $(\mathrm{P}<0.001)$ (Tables 3,4).

In addition, age $(\mathrm{r}=0.298, \mathrm{P}=0.001)$, height $(\mathrm{r}=-0.155$, $\mathrm{P}=0.046)$, body weight $(\mathrm{r}=0.289, \mathrm{P}=0.001), \mathrm{BMI}(\mathrm{r}=0.387$, $\mathrm{P}=0.001)$, age at menarche $(\mathrm{r}=0.185, \mathrm{P}=0.017)$, and $\mathrm{PA}-$ MSHA preparation $(\mathrm{P}<0.001)$ were significantly correlated with postoperative drainage time, and the application of PA-MSHA preparation significantly reduced this $(\mathrm{P}<0.001)$ (Tables 3,4).

\section{Multivariate analysis}

Age, body weight, BMI, age at menarche, menopause, and PA-MSHA preparation were included in the regression analysis as risk factors for postoperative total drainage volume, and age, height, weight, BMI, age at menarche, and PA-MSHA preparation were included in the regression analysis as risk factors for postoperative drainage time. The results showed that age, BMI, and PA-MSHA preparation were significantly correlated with postoperative total drainage volume and drainage time (Table 5).

\section{Stratified analysis}

The postoperative total drainage volume and drainage time were divided into two groups according to the median. In the stratified analysis, patients were divided into a nonelderly group (age $<60$ years) and elderly group (age $\geq 60$ years) according to age, a normal weight group $\left(\mathrm{BMI}<25 \mathrm{~kg} / \mathrm{m}^{2}\right)$ and overweight group (BMI $\geq 25 \mathrm{~kg} / \mathrm{m}^{2}$ ) according to BMI, and a PA and non-PA group according to the use of PA-MSHA preparation. The results showed that age, BMI, and PA-MSHA preparation use were independent factors affecting the postoperative total drainage volume and drainage time of $\mathrm{BC}$ patients (Table 6).

\section{Comparison of efficacy and complications in the PA and non-PA groups}

The use of PA-MSHA preparation significantly reduced the postoperative drainage volume and drainage time and reduced the occurrence of seroma after extubation $(\mathrm{P}<0.001)$. Regarding the occurrence of seroma after extubation, there were five cases $(4.31 \%)$ in the PA group and seven (14.29\%) in the non-PA group, and the incidence was significantly lower in the PA group $\left(\chi^{2}=5.083, \mathrm{P}=0.024\right)$.

Fever, wound infection, and flap necrosis occurred in both the PA and non-PA groups, but there were no significant differences $(\mathrm{P}>0.05)$ (Table 7), while eight cases of fever occurred in the PA group, but all were below $39^{\circ} \mathrm{C}$ and the fever resolved within 24 hours. All wound infections were local surgical infections that responded well to daily dressing, and no secondary suture or intravenous injection of antibiotics was required. All cases of flap necrosis had a small range, and after treatment by the wound care physical therapists, the flap necrosis healed well without surgical 
Table 3 Analysis of the correlation of continuous variables with postoperative total drainage volume and drainage time

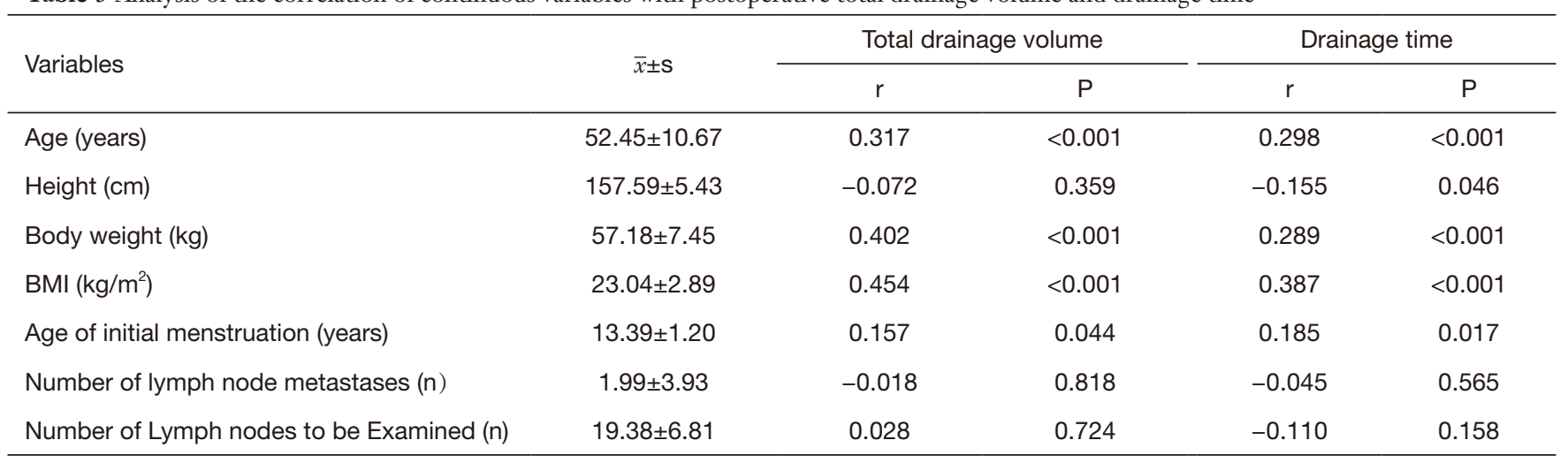

Table 4 Analysis of the correlation of categorical variables with postoperative total drainage volume and drainage time

\begin{tabular}{|c|c|c|c|c|c|c|c|}
\hline Variables & Cases & \multicolumn{3}{|c|}{ Total drainage volume } & \multicolumn{3}{|c|}{ Drainage time } \\
\hline Menopause & & & -2.335 & 0.020 & & -1.494 & 0.137 \\
\hline No & 78 & $597.63 \pm 387.53$ & & & $14.87 \pm 5.53$ & & \\
\hline Yes & 87 & $739.59 \pm 463.38$ & & & $16.27 \pm 6.56$ & & \\
\hline$\geq 2$ & 122 & $662.27 \pm 442.51$ & & & $15.30 \pm 5.79$ & & \\
\hline$<2$ & 43 & $697.52 \pm 415.80$ & & & $16.50 \pm 7.03$ & & \\
\hline ER & & & 0.224 & 0.823 & & -1.236 & 0.218 \\
\hline- & 32 & $657.27 \pm 347.20$ & & & $15.33 \pm 6.01$ & & \\
\hline+ & 124 & $656.25 \pm 437.32$ & & & $14.94 \pm 5.41$ & & \\
\hline Ki67 & & & -1.296 & 0.195 & & -1.197 & 0.231 \\
\hline$<20 \%$ & 56 & $785.29 \pm 527.33$ & & & $16.75 \pm 7.19$ & & \\
\hline$\geq 20 \%$ & 109 & $614.83 \pm 363.63$ & & & $15.04 \pm 5.39$ & & \\
\hline Left/right & & & -0.569 & 0.570 & & 1.010 & 0.282 \\
\hline Left & 82 & $709.39 \pm 459.19$ & & & $16.13 \pm 6.52$ & & \\
\hline Right & 83 & $636.41 \pm 403.49$ & & & $15.11 \pm 5.64$ & & \\
\hline \multicolumn{3}{|c|}{ Subclavian lymph node dissection } & -0.343 & 0.732 & & -0.104 & 0.918 \\
\hline
\end{tabular}

ER, estrogen receptor; PR, progesterone receptor; Ki67, Ki-67 antigen; PA-MSHA, Pseudomonas aeruginosa-mannose sensitive hemagglutinin. 
Table 5 Results of multivariate analysis of postoperative total drainage volume and drainage time

\begin{tabular}{|c|c|c|c|c|c|c|c|c|}
\hline Variables & \multicolumn{4}{|c|}{ Total drainage volume } & \multicolumn{4}{|c|}{ Drainage time } \\
\hline Age & 9.200 & 2.818 & 3.265 & $<0.001$ & 0.128 & 0.041 & 3.094 & 0.002 \\
\hline BMI & 60.172 & 10.380 & 5.797 & $<0.001$ & 0.709 & 0.152 & 4.665 & $<0.001$ \\
\hline PA-MSHA & 381.228 & 57.089 & 6.678 & $<0.001$ & 5.312 & 0.847 & 6.269 & $<0.001$ \\
\hline
\end{tabular}

PA-MSHA, Pseudomonas aeruginosa-mannose sensitive hemagglutinin; PRC, partial regression coefficient.

Table 6 Relationships of variables with total drainage volume and drainage time

\begin{tabular}{|c|c|c|c|c|c|c|}
\hline Variables & \multicolumn{3}{|c|}{ Total drainage volume } & \multicolumn{3}{|c|}{ Drainage time } \\
\hline \multicolumn{7}{|c|}{ Stratified by age } \\
\hline BMI & 7.835 & 2.964-20.716 & $<0.001$ & 5.840 & $2.153-15.844$ & $<0.001$ \\
\hline PA-MSHA & 11.139 & $4.735-26.200$ & $<0.001$ & 8.135 & $3.421-19.345$ & $<0.001$ \\
\hline Age & 3.149 & $1.472-6.733$ & 0.004 & 2.309 & $1.098-4.858$ & 0.037 \\
\hline PA-MSHA & 15.300 & $6.130-38.187$ & $<0.001$ & 9.821 & $3.994-24.152$ & $<0.001$ \\
\hline \multicolumn{7}{|c|}{ Stratified by PA-MSHA intervention } \\
\hline Age & 4.028 & $1.766-9.189$ & 0.001 & 2.735 & $1.239-6.041$ & 0.012 \\
\hline
\end{tabular}

PA-MSHA, Pseudomonas aeruginosa-mannose sensitive hemagglutinin.

Table 7 Comparison of efficacy and complications between the two groups

\begin{tabular}{lcccc}
\hline Characteristics & PA group $n=116$ & non-PA group $n=49$ & $t / z$ & $X^{2}$ \\
\hline Total drainage volume $(\mathrm{mL})$ & $546.48 \pm 279.971$ & $971.44 \pm 566.694$ & -5.519 & $<0.001$ \\
Drainage time (days) & $13.88 \pm 4.388$ & $19.73 \pm 7.510$ & -5.539 & 0.024 \\
$\begin{array}{l}\text { Incidence of seroma after } \\
\text { extubation (cases) }\end{array}$ & 5 & 7 & 5.083 \\
Fever (cases) & 8 & 3 & 0.033 \\
Wound infection (cases) & 1 & 2 & 2.000 & 0.855 \\
Skin flap necrosis (cases) & 1 & 1 & 0.400 & 0.527 \\
\hline
\end{tabular}

PA, Pseudomonas aeruginosa.

intervention.

\section{Hospital stay}

All patients underwent MRM and were discharged 3 days after surgery. All patients received surgical follow-up and regular cancer treatment.

\section{Mortality}

No deaths were reported during the follow-up period of this study. 


\section{Discussion}

Surgery is one of the essential treatments for BC. With the continuous advancements in BC treatment, MRM has gradually been replaced by breast conservation therapy and sentinel lymph node biopsy (10-15). However, in undeveloped countries, most patients still choose MRM for personal reasons (16), and postoperative complications, such as a large amount of drainage, long indwelling time of the drainage tube, and seroma after extubation, severely interfere with the daily lives of patients, delay further treatment (such as radiotherapy and chemotherapy), and affect overall social and medical costs.

Various surgical methods have been trialed, such as different methods of negative pressure drainage, quilting suture (17), replacing electric scalpels with ultrasonic scalpels $(18,19)$, upper limb immobilization on the affected side, injection of streptococcal preparation OK-432 (20), and fibrin sealant (21), to reduce the drainage time after BC surgery and avoid seroma after extubation. However, no optimal or completely effective method has been established to date due to limitations such as increased operative time, increased movement limitations of the upper extremity, increased risk of pain and subcutaneous sclerosis, and small sample sizes. In addition, there is a lack of data exploring the use of preventive techniques for reducing postoperative drainage time for BC. A comprehensive analysis of factors presumed to affect drainage time could ultimately lead to the development of effective methods for its reduction, improve quality of life, reduce the number of postoperative follow-up visits, reduce overall medical costs, and buy time for further treatment of the tumor.

The results of this study showed that age was positively correlated with increased postoperative total drainage volume and prolonged drainage time, with patients over 60 at greater risk of both than younger patients. Zieliński et al. (22) reported that prolonged postoperative drainage times associated with BC were positively correlated with age, and Lee et al. (23) showed that advanced age was an important predictor of prolonged drainage time. Other studies (24-26) have also reported a correlation between age and surgical outcome in BC and are consistent with our results. The effect of age as an important factor affecting the drainage volume and drainage time of patients undergoing MRM may be because the blood supply in the skin of elderly patients is slightly worse than that of young patients, increasing the likelihood of postoperative insufficiency. In addition, the glandular tissue of the breast in elderly women is obviously degenerated and is basically composed of adipose tissue (27), and the medical compliance of elderly adults is worse than that of younger patients (28), which may be associated with earlier upper limb movement in elderly patients.

Banerjee et al. (29) found that compared with patients with a higher BMI, those with a BMI $<30$ had significantly lower average total drainage volumes and daily drainage volumes, and Inoue et al. (30) reported that patients with a high BMI had a large drainage volume and a long drainage time. Lee et al. (23) also reported a significant positive correlation between BMI and drainage time. The above results are supported by those of the present study which showed a significant correlation between obesity and a high total drainage volume and long drainage time, both of which were significantly higher in overweight patients $(B M I \geq 25)$ than in those of normal-weight patients. In industrialized countries, the number of overweight people is increasing, and in addition to reducing the drainage time for obese BC patients undergoing mastectomy, preventive measures such as weight reduction may also reduce the incidence of postoperative complications.

In this study, some patients received local spraying of the surgical area with PA-MSHA preparation. Surprisingly, this significantly reduced the postoperative total drainage volume and drainage time as well as the incidence of seroma and was an independent factor that affected the postoperative total drainage volume and drainage time of BC patients. Patients in the PA group had earlier extubation $(13.88 \pm 4.388$ vs. $19.73 \pm 7.510$ days, $\mathrm{P}<0.001)$ and a lower incidence of seroma $(4.31 \%$ vs. $14.29 \%, \mathrm{P}=0.024)$ than those in the non-PA group. Zhu et al. $(31,32)$ reported PA-MSHA preparation could reduce the occurrence of postoperative chylous fistula and postoperative drainage time in thyroid carcinoma, which supports our results. The incidence of seroma in our study was also significantly lower than that reported by Myint (14) (14.3\% in the suture group and $30 \%$ in the conventional group), and that reported by Kong et al. (19).

As PA-MSHA preparation is an inactivated bacterial preparation, its intraoperative local spraying can activate innate immune dendritic cells and macrophages and stimulate immune cells to secrete cytokines, such as tumor necrosis factor (TNF)- $\alpha$, interleukin (IL)-1, IL-6, and interferon (IFN)- $\gamma$. This can cause the central circuitries for body temperature regulation to raise the body temperature at designated sites, resulting in a transient fever, which explains why fever is the most common adverse reaction (3-5,31-33). 
In this study, the number of fever cases in the PA group was higher than in the non-PA group (eight cases vs. three cases, $\mathrm{P}=0.855$ ), and occurred $6-12$ hours after drug administration, although it was no higher than $39^{\circ} \mathrm{C}$. Fever was treated with physical hypothermia, there was no need for antibiotics, and spontaneous remission occurred within 24 hours after surgery, indicating PA-MSHA preparation was generally safe and did not increase the occurrence of other complications. Nevertheless, although PA-MSHA preparation can effectively shorten drainage time and prevent the occurrence of seroma, body temperature should be closely monitored after its application.

As this was a retrospective study, selection bias may have occurred, and a prospective evaluation based on a large patient population is required to strengthen the results. Quantification of the relationships between postoperative drainage time and the quality of life of patients also requires more comprehensive individual-level data.

\section{Conclusions}

According to the results of this study, obese and elderly patients are at a significantly high risk of having a high drainage volume and a long drainage time after MRM. PA-MSHA preparation could effectively reduce the drainage volume, shorten the drainage time, and prevent seroma. Furthermore, it was safe and did not increase the complications of patients, suggesting it is worthy of clinical promotion. Therefore, for BC patients aged over 60 years and with a $\mathrm{BMI} \geq 25$, intraoperative local spraying of PAMSHA preparation on wounds to reduce the postoperative drainage time provides a valuable option and may be an important protective factor for the prevention of seroma.

\section{Acknowledgments}

Funding: None.

\section{Footnote}

Reporting Checklist: The authors have completed the STROBE reporting checklist. Available at https://dx.doi. org/10.21037/gs-21-697

Data Sharing Statement: Available at https://dx.doi. org/10.21037/gs-21-697

Conflicts of Interest: All authors have completed the ICMJE uniform disclosure form (available at https://dx.doi. org/10.21037/gs-21-697). The authors have no conflicts of interest to declare.

Ethical Statement: The authors are accountable for all aspects of the work in ensuring that questions related to the accuracy or integrity of any part of the work are appropriately investigated and resolved. The study was approved by the ethics committee of the West China Hospital of Sichuan University [NO. 2020(620)]. Written informed consent was obtained prior to the study. The study was conducted in accordance with the Declaration of Helsinki (as revised in 2013).

Open Access Statement: This is an Open Access article distributed in accordance with the Creative Commons Attribution-NonCommercial-NoDerivs 4.0 International License (CC BY-NC-ND 4.0), which permits the noncommercial replication and distribution of the article with the strict proviso that no changes or edits are made and the original work is properly cited (including links to both the formal publication through the relevant DOI and the license). See: https://creativecommons.org/licenses/by-nc-nd/4.0/.

\section{References}

1. Sung H, Ferlay J, Siegel RL, et al. Global Cancer Statistics 2020: GLOBOCAN Estimates of Incidence and Mortality Worldwide for 36 Cancers in 185 Countries. CA Cancer J Clin 2021;71:209-49.

2. Lohani KR, Kumar C, Kataria K, et al. Role of tranexamic acid in axillary lymph node dissection in breast cancer patients. Breast J 2020;26:1316-20.

3. Zhang C, Zhang Z, Wang L, et al. Pseudomonas aeruginosa-mannose sensitive hemagglutinin injection treated cytokine-induced killer cells combined with chemotherapy in the treatment of malignancies. Int Immunopharmacol 2017;51:57-65.

4. Li T, Dong ZR, Guo ZY, et al. Mannose-mediated inhibitory effects of PA-MSHA on invasion and metastasis

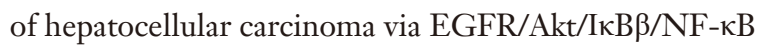
pathway. Liver Int 2015;35:1416-29.

5. Zhang M, Luo F, Zhang $Y$, et al. Pseudomonas aeruginosa mannose-sensitive hemagglutinin promotes $\mathrm{T}$-cell response via toll-like receptor 4-mediated dendritic cells to slow tumor progression in mice. J Pharmacol Exp Ther 2014;349:279-87.

6. Gondo N,Sawaki M, Hattori $M$, et al. Impact of BMI $f$ 
or clinical outcomes in Japanese breastcancer patients. Jpn J Clin Oncol 2020;50:230-240.

7. Physical status: the use and interpretation of anthropometry. Report of a WHO Expert Committee. World Health Organ Tech Rep Ser 1995;854:1-452.

8. Marquez JE, Kapadia K, Ghosh K, et al. Efficacy of Fibrin Sealants in Preventing Seroma Formation in Reduction Mammaplasty: A Single Surgeon's Experience. Ann Plast Surg 2020;85:S41-3.

9. Srivastava V, Basu S, Shukla VK. Seroma formation after breast cancer surgery: what we have learned in the last two decades. J Breast Cancer 2012;15:373-80.

10. van Dongen JA, Voogd AC, Fentiman IS, et al. Long-term results of a randomized trial comparing breast-conserving therapy with mastectomy: European Organization for Research and Treatment of Cancer 10801 trial. J Natl Cancer Inst 2000;92:1143-50.

11. Fisher B, Anderson S, Bryant J, et al. Twenty-year followup of a randomized trial comparing total mastectomy, lumpectomy, and lumpectomy plus irradiation for the treatment of invasive breast cancer. $\mathrm{N}$ Engl J Med 2002;347:1233-41.

12. Veronesi U, Cascinelli N, Mariani L, et al. Twentyyear follow-up of a randomized study comparing breastconserving surgery with radical mastectomy for early breast cancer. N Engl J Med 2002;347:1227-32.

13. Arriagada R, Lê MG, Guinebretière JM, et al. Late local recurrences in a randomised trial comparing conservative treatment with total mastectomy in early breast cancer patients. Ann Oncol 2003;14:1617-22.

14. Poggi MM, Danforth DN, Sciuto LC, et al. Eighteenyear results in the treatment of early breast carcinoma with mastectomy versus breast conservation therapy: the National Cancer Institute Randomized Trial. Cancer 2003;98:697-702.

15. Atalay C. New concepts in axillary management of breast cancer. World J Clin Oncol 2014;5:895-900.

16. Chen VE, Greenberger BA, Shi Z, et al. Post-mastectomy and post-breast conservation surgery pain syndrome: a review of etiologies, risk prediction, and trends in management. Transl Cancer Res 2020;9:S77-85.

17. Myint ST, Khaing KS, Yee W, et al. Quilting suture versus conventional closure in prevention of seroma after total mastectomy and axillary dissection in breast cancer patients. ANZ J Surg 2020;90:1408-13.

18. Zhang Z, Li L, Pang Y, et al. Comparison of harmonic scalpel and conventional technique in the surgery for breast cancer: A systematic review and meta-analysis.
Indian J Cancer 2018;55:348-58.

19. Michalik T, Matkowski R, Biecek P, et al. The use of ultrasonic scalpel lowers the risk of post-mastectomy seroma formation in obese women. J Cancer 2019;10:3481-5.

20. Kong D, Liu Y, Li Z, et al. OK-432 (Sapylin) Reduces Seroma Formation After Axillary Lymphadenectomy in Breast Cancer. J Invest Surg 2017;30:1-5.

21. Chang YT, Shih SL, Loh EW, et al. Effects of Fibrin Sealant on Seroma Reduction for Patients with Breast Cancer Undergoing Axillary Dissection: Meta-Analysis of Randomized Controlled Trials. Ann Surg Oncol 2020;27:5286-95.

22. Zieliński J, Jaworski R, Irga N, et al. Analysis of selected factors influencing seroma formation in breast cancer patients undergoing mastectomy. Arch Med Sci 2013;9:86-92.

23. Lee KT, Hong SH, Jeon BJ, et al. Predictors for Prolonged Drainage following Tissue Expander-Based Breast Reconstruction. Plast Reconstr Surg 2019;144:9e-17e.

24. Khan S, Khan S, Chawla T, et al. Harmonic scalpel versus electrocautery dissection in modified radical mastectomy: a randomized controlled trial. Ann Surg Oncol 2014;21:808-14.

25. Sanguinetti A, Docimo G, Ragusa M, et al. Ultrasound scissors versus electrocautery in axillary dissection: our experience. G Chir 2010;31:151-3.

26. Vinton AL, Traverso LW, Jolly PC. Wound complications after modified radical mastectomy compared with tylectomy with axillary lymph node dissection. Am J Surg 1991;161:584-8.

27. Ding YJ, Zhao XS , Zhu HR, et al. Features of infrared radiographic images of senile breast cancer. Practical Geriatrics 1996;(2):88-9.

28. Nguyen NP, Karlsson U, Oboite E, et al. Older breast cancer undertreatment: unconscious bias to undertreatpotential role for the international geriatric radiotherapy group? Transl Cancer Res 2020;9:S228-35.

29. Banerjee D, Williams EV, Ilott J, et al. Obesity predisposes to increased drainage following axillary node clearance: a prospective audit. Ann R Coll Surg Engl 2001;83:268-71.

30. Inoue $\mathrm{Y}$, Yamashita $\mathrm{N}$, Ueo $\mathrm{H}$, et al. The Clinical Usefulness of the LigaSure ${ }^{\mathrm{TM}}$ Small Jaw in Axillary Lymph Node Dissection in Patients with Breast Cancer. Anticancer Res 2018;38:2359-62.

31. Genpeng L, Jinen $\mathrm{S}$, Tao $W$, et al. Intraoperative application of inactivated Pseudomonas aeruginosa in patients undergoing lateral neck dissection for metastatic 
thyroid cancer: A randomized, parallel group, placebocontrolled trial. Surgery 2020;168:340-6.

32. Chen Q, Zou X, Ma Y, et al. Pseudomonas aeruginosamannose sensitive hemagglutinin injection therapy for the treatment of chyle fistula following neck dissection. Head

Cite this article as: Long Q, Zhang J, Qi J, Fan Y, Li H. Analysis of factors influencing postoperative drainage time in breast cancer. Gland Surg 2021;10(12):3272-3282. doi: 10.21037/ gs-21-697
Neck 2020;42:725-31.

33. Long Q, Zhang J, Wei B, et al. The effect of subcutaneous local spraying of Pseudomonas aeruginosa preparation to reduce postoperative drainage time in patients with breast cancer. Gland Surg 2020;9:2064-70. 